\title{
ERRATA
}

\section{CLINICS 2011;66(3):493-499}

Page 493

Replace Juliana Hypólito Silva, I de Sá BC, ${ }^{\mathrm{II}}$ Alexandre Leon Ribeiro de Ávila, ${ }^{\mathrm{II}}$ Gilles Landman, ${ }^{\mathrm{II}}$ João Pedreira Duprat Neto ${ }^{\mathrm{II}}$

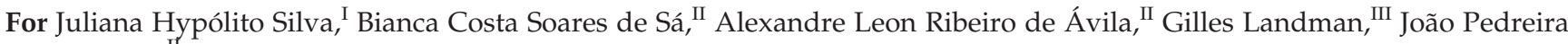
Duprat Neto ${ }^{\text {II }}$

Page 493 (Abstract)

Replace Silva JH, de Sá BCS, Avila ALR, Landman G, Duprat Neto JP. Atypical mole syndrome and dysplastic nevil: identification of populations at risk for developing melanoma - review article. Clinics. 2011;66(3):493-499.

For Silva JH, de Sá BC, Avila ALR, Landman G, Duprat Neto JP. Atypical mole syndrome and dysplastic nevil: identification of populations at risk for developing melanoma - review article. Clinics. 2011;66(3):493-499.

\section{CLINICS 2011;66(5):793-799}

\section{Page 793 (Abstract/Results)}

Replace These results show that hotspot mutations in the PI3K, JAK2, FLT3 and NPM1 genes are not common in MDS patients; nevertheless, JAK2 mutations may be present in myelodysplasia during disease progression.

For In the genes studied, no mutations were detected in the patients at the time of diagnosis. One patient with chronic myelomonocytic leukemia was heterozygous for a Janus kinase 2 mutation after disease progression.

\section{CLINICS 2011;66(5):843-848}

\section{Page 843}

Replace Chemical composition of the essential oil from kelussia odoratissima mozaff. and the evaluation of its sedative and anxiolytic effects in mice

For Chemical composition of the essential oil from Kelussia odoratissima Mozaff. and the evaluation of its sedative and anxiolytic effects in mice

Replace ${ }^{I}$ Department of Pharmacognosy, School of Pharmacy, Isfahan University of Medical Sciences, Isfahan, Iran. II Department of Pharmacology, School of Pharmacy, Isfahan University of Medical Sciences, Isfahan, Iran. III Isfahan Pharmaceutical Sciences Research Center, School of Pharmacy, Isfahan University of Medical Sciences, Isfahan, Iran.

For ${ }^{\text {I }}$ Department of Pharmacology, School of Pharmacy, Isfahan University of Medical Sciences, Isfahan, Iran. ${ }^{\mathrm{II}}$ Department

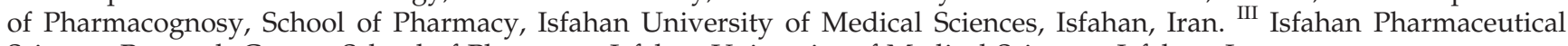
Sciences Research Center, School of Pharmacy, Isfahan University of Medical Sciences, Isfahan, Iran. 